\title{
LAS NORMAS MORALES QUE NO ADMITEN EXCEPCIONES*
}

\author{
JoAQuín García-Huidobro CORREA ${ }^{1}$
}

RESUMEN: En un célebre pasaje del libro II de la Ética a Nicómaco, Aristóteles afirma que bay ciertas acciones respecto de las que no cabe un justo medio, sino que siempre constituyen un desorden y son, por tanto, ilícitas en todas las circunstancias. Esta idea de unos absolutos morales, que ba inspirado buena parte de la tradición ética de Occidente, ha sido fuertemente cuestionada por diversos autores, que sostienen que ella expresa nada más que una tautología o que es sencillamente falsa, al no hacer justicia a la complejidad de la acción bumana y sus circunstancias. En este artículo se procura mostrar que bay buenas razones para mantener esa vieja idea aristotélica, que permite explicar mucho mejor que sus detractores los alcances de nuestra responsabilidad.

\footnotetext{
Palabras clave: Bioética - Responsabilidad - Utilitarismo - Absolutos morales.
}

ABSTRACT: In a well-known passage of the II book of Etbics to Nicomacus, Aristotle states that there are certain actions that cannot be considered in their fair balf, but always constitute a disorder and are, thus, illicit under every circumstance. The idea of absolute morals, that has inspired an important part of the etbics in the Western Hemisphere bas been strongly questioned by different authors, that maintain that it expresses only a tautology or that it is simply false, since it doesn't meet up to the complexity of buman actions and its circumstances. This article intends to show that there are good reasons to sustain this old Aristotelian idea which explains much better than its detractors the scope of our responsibility.

KEY wORDs: Bioethics - Responsibility - Utilitarianism - Absolute morals.

SUMARIO: Introducción. I. Los límites de la relatividad en materias éticas. II. Objeciones en contra de los absolutos morales. III. El alcance de nuestra responsabilidad

* Este trabajo forma parte de una investigación más amplia, realizada con el apoyo de Fondecyt (proyectos 1010182 y 1040343 ).

1 Abogado. Doctor en Filosofía por la Universidad de Navarra. Profesor de la Facultad de Derecho de la Universidad de los Andes, Chile. Correo electrónico: jgh@uandes.cl Artículo recibido el 20 de mayo de 2005. Aprobado por el Comité Editorial el 18 de octubre de 2005. 


\section{INTRODUCCIÓN}

Uno de los puntos más debatidos en la discusión ética contemporánea es el de si existen algunas normas morales que no están sujetas a excepciones ${ }^{2}$. Es decir, si hay conductas que no pueden realizarse ni aun a pretexto de circunstancias extraordinarias. En este trabajo se presentará el problema, (I) se expondrán algunas objeciones contra los absolutos morales, sus réplicas, (II) para terminar con el alcance de nuestra responsabilidad, (III) cuestión que, según parece, está en el fondo de la discusión entre las éticas de corte utilitaristas y aquellas que se inspiran en la Tradición Central de Occidente, ya sean de raíz griega y medieval, como también de corte kantiano.

\section{LOS LÍMites DE LA RELATIVIDAD EN MATERIAS ÉtiCAS}

Muchas veces se ha dicho que la ética de Aristóteles, y también la de su discípulo Tomás de Aquino, no es una ética de la ley, sino de la virtud ${ }^{3}$. Pero, al mismo tiempo, cabe reconocer que toda ética de la virtud estará necesariamente marcada por una cierta relatividad. En efecto, el justo medio en que las virtudes consisten es un medio

2 Un resumen de los diversos argumentos en: Finnis, J. Absolutos morales. Barcelona: Ediciones Internacionales Universitarias, 1992; MAY, W. (ed), Principios de vida moral. Barcelona: Ediciones Internacionales Universitarias, 1990, en especial los capítulos IV y V, que incluyen trabajos de F. S. Carney, G. Grisez y otros; Spaemann, R. Felicidad y benevolencia Madrid: Rialp, 1991; Curran, Ch., MCCormick, R.A. (eds.), Readings in Moral Theology 1. Moral Norms and Catholic Tradition New York: Paulist Press, 1979, P. Ramsey, P., McCormick, R.A. (eds), Doing Evil to Achieve Good Chicago: Loyola University Press, 1978; Molina, E. La Moral entre la Convicción y la Utilidad. Pamplona: Eunsa, 1996. También constituye una obra fundamental: Pinkaers, S. Ce qu'on en peut jamais faire. La question des actes intrinsèquement mauvais. Histoire et discussion Fribourg (Suisse): Éditions Universitaires de Fribourg, 1986. Entre las obras que más al día ponen la discusión de la última década son importantes: Baron, M. et al., Three Methods of Ethics - A Debate: For and Against: Consequences, Maxims, and Virtues. Oxford: Blackwell, 1997; Petrit, Ph., (ed), Consequentialism (International Research Library of Philosophy, Vol, 6). Dartmouth: Aldershot, 1993; Roberts, M.A. Child Versus Childmaker: Future Persons and Present Duties in Ethics and the Law (Studies in Social, Political, and Legal Philosophy) Lanham: Rowman \& Littlefield, 1998; Cummiskey, D. Kantian Consequentialism. New York: OUP, 1996, y CARlson, E. Consequentialism Reconsidered Dordrecht: Kluwer Academic Publishers, 1995; Herrera, H. Verdad y práctica. Cinco ensayos sobre la fundamentación de la praxis. Valparaíso: Edeval, 2000. En estos textos se cita abundante bibliografía. Los argumentos que se entregarán en este artículo están basados, fundamentalmente, en las ideas de Robert Spaemann y John Finnis.

3 Una reseña del debate actual sobre la virtud en: AвB⿳亠, G. Felicidad, vida buena y virrud. Ensayo de filosofía moral. Barcelona: Ediciones Internacionales Universitarias, 1992, 85138; también: Nussbaum, M. Love's Knowledge Oxford: Oxford University Press, 1990. 
racional, es decir, no está normalmente determinado por una cantidad externa, sino que debe ser establecido prudencialmente, atendiendo a las características del sujeto y su situación. Aristóteles pone el ejemplo de Milón, un voluminoso atleta que, según se decía, debía consumir un vacuno al día. Todos tenemos que ser templados, pero lo que eso conlleva en la práctica difiere de persona en persona. Probablemente lo templado para el lector será comer bastante menos carne que Milón.

Lo que se dice de la templanza lo afirmamos de la laboriosidad, la fortaleza y todas las demás virtudes. Sin embargo, advierte Aristóteles, que hay ciertas acciones y pasiones que no admiten un más y un menos a la hora de su calificación moral, sino que siempre suponen un desorden:

"no toda acción ni toda pasión admite el término medio, pues hay algunas cuyo mero nombre implica la maldad, por ejemplo, la malignidad, la desvergüenza, la envidia; y entre las acciones el adulterio, el robo y el homicidio. Todas estas cosas y las semejantes a ellas se llaman así por ser malas en sí mismas, no sus excesos ni sus defectos. Por tanto, no es posible nunca acertar con ellas sino que siempre se yerra. Y no está el bien o el mal, cuando se trata de ellas, por ejemplo, en cometer adulterio con la mujer debida y cuando y como es debido, sino que, en absoluto, el hacer cualquiera de estas cosas está mal" 4 .

Vemos, entonces, que aquí cesa cualquier relatividad en la ética. Estamos ante un límite infranqueable. No es casual, entonces, que esas normas morales estén expresadas de manera negativa: "no matarás a un inocente" (homicidio), "no mentirás", "no adulterarás", etc., de modo que los hombres están en condiciones de saber con relativa facilidad cuándo han transgredido ese límite. En cambio, en las normas expresadas de manera positiva (por ejemplo "honra a tus padres"), vemos que nunca se agota su contenido, que siempre pueden ser cumplidas de una manera más perfecta.

Si lo dicho por Aristóteles es verdad, entonces estas normas negativas siempre indican algo que es contrario a la razón. Esta contrariedad no puede ser suprimida por un más y un menos, o por un cambio de circunstancias o motivaciones: se trata de acciones que no son ordenables al bien de la persona entera.

ARISTóteles, Ética a Nicómaco(EN) II 6, 1107 a 9-17. 


\section{OBJECIONES EN CONTRA DE LOS ABSOLUTOS MORALES}

Si existen normas morales de carácter absoluto, entonces jamás será lícito realizar las acciones que ellas indican. $\mathrm{Ni}$ aun con el pretexto de circunstancias extraordinarias se podrá cometer un homicidio, alegrarse del mal ajeno o mentir. Las circunstancias son muy importantes en moral, pero en estos casos cesa todo cálculo de circunstancias, lo mismo que de las consecuencias futuras de la acción. Quien se halla ante la posibilidad de realizar una de esas acciones, deberá excluirla por principio de su curso de decisión, sin entrar a considerar si en ese caso, por una determinada circunstancia o por los efectos benéficos que podría producir, cabría llevarla a cabo. No es lícito hacer el mal para producir el bien.

Una doctrina tal, que es la que mantiene la tradición ética, desde Aristóteles hasta nuestros días, pasando por los escolásticos y muchos modernos, como Kant, dista de ser pacífica. Así, numerosos autores la han hecho objeto de crítica o la han interpretado de modo que permita, bajo ciertas condiciones, realizar algunos de esos actos. Se dice, por ejemplo, que esas normas, en el fondo, encierran tautologías. Si incurrir en homicidio significa matar injustamente a una persona, o si cometer adulterio significa mantener relaciones sexuales ilícitas fuera del matrimonio, resulta obvio que esos actos son ilícitos, ya que por definición es ilícito realizar algo ilícito. Dicho con otras palabras, si la evaluación negativa (el carácter de ilícita) está incluida en la descripción de la conducta, es evidente que esa acción deberá ser excluida de modo necesario. De esta manera, los absolutos morales serían normas superfluas, que se limitarían a decirnos lo que ya sabemos: que es malo lo malo.

Sin embargo, no hay tal tautología. No es que la conducta se describa como poseyendo una maldad moral y luego se diga que es mala, sino que se afirma que la conducta misma es siempre ilegítima. El homicidio es matar directa e intencionadamente a un inocente, y punto. Hasta aquí la descripción de la conducta. Eso es lo que entendemos por homicidio y de eso se dice que es siempre malo, sean cuales fueren las circunstancias. La evaluación, por tanto, viene después. Otro tanto sucede con el adulterio, que no significa tener relaciones sexuales extramaritales ilícitas, sino simplemente tenerlas con una persona distinta del propio cónyuge.

Con todo, la dificultad más habitual para admitir la existencia de las normas morales inexcepcionables no es la indicada, sino una mucho más práctica: ¿no resultará exagerado excluir por principio ciertas conductas, cuando en determinadas ocasiones su realización nos permite obtener bienes mayores? ¿No sería razonable dar muerte a un inocente si ese es el precio exigido por un terrorista para no matar a decenas de rehenes? ¿O no podría ser el adulterio, en ciertos casos, un medio de 
liberar determinadas tensiones psíquicas $\mathrm{y}$, por tanto, una manera de salvar a un matrimonio de una crisis mayor? Y el aborto, ¿no resulta la única manera para salir adelante en una situación de miseria o cuando la concepción es consecuencia de una violación?

En torno a estas cuestiones se ha originado una amplia discusión, que no se puede detallar en estas páginas. Baste con decir que las cosas no son tan sencillas como podrían parecer. Pensemos, por ejemplo, en el chantaje del terrorista: ¿quién nos asegura que si cumplimos sus exigencias liberará a los rehenes? Y aunque los liberase, ¿quién asegura que, si cedemos, no se extenderán esas prácticas y nos veamos entonces afectados por una masiva difusión de los secuestros, con mucho más sufrimientos y muertes que los que se habrían producido si no hubiésemos accedido a realizar algo malo para conseguir un bien mayor? Además, la liberación de los rehenes no se producirá por nuestra acción homicida, sino por la mera voluntad del terrorista: hagamos o no lo que nos pide, él puede cumplir o no su amenaza. No hay relación de causalidad. Ni siquiera podemos decir, en sentido estricto, que hacemos algo malo para producir un bien. Más bien estaremos haciendo algo malo y mantendremos la esperanza de que, por causas diversas, se produzca un bien. Pero, que se produzca o no, es un hecho que no depende de nuestra voluntad. Estamos en presencia de dos acciones diferentes y en caso alguno se puede decir que la multitud se salvó porque se dio muerte a un inocente.

Además, como nuestra voluntad está radicalmente involucrada en cada una de nuestras elecciones, el hecho de elegir consciente y deliberadamente algo que no es ordenable al bien del hombre produce en nosotros una mala voluntad, nos hace peores personas. Determinadas circunstancias o una buena intención pueden atenuar la malicia, pero no son suficientes como para suprimirla.

\section{EL ALCANCE DE NUESTRA RESPONSABILIDAD}

En el fondo, lo que se está discutiendo es a qué estamos obligados y cuál es el ámbito de nuestra responsabilidad. ¿Es nuestra obligación hacer el bien o producirlo, actuar bien o dar origen a buenos resultados?, ¿respondemos de las acciones que dependen de nuestra libertad o de estados de cosas futuras que se originan debido a múltiples factores además de nuestra voluntad?

Si nuestra obligación es hacer el bien y evitar el mal en el marco de cada una de nuestras acciones, entonces sabemos bastante bien de qué respondemos. Si alguien nos dice que si hubiésemos dado muerte a la madre que educaba mal al hijo no se habría producido nunca un tirano, nosotros podríamos responder que el matar directamente a un inocente 
es algo que se halla fuera de nuestro alcance. Así como no podemos transformar el fuego en agua o las balas en algodones, tampoco podemos cometer homicidio. Ambas cosas son imposibles, solo que una es física y la otra moralmente imposible.

En cambio, si nuestra obligación es producir el bien, entonces debemos actuar no en función de lo que nos indique nuestra conciencia en ese caso, sino de lo que resulte de un cálculo, a saber, de la suma de las consecuencias positivas menos la suma de las consecuencias negativas que se producirán como resultado de esa acción. Esto, a nuestro juicio, es imposible, o al menos indeseable.

Es imposible porque no conocemos el futuro. Hasta los resultados más cercanos y probables de nuestros actos pueden resultar muy diferentes de lo que preveíamos, ya que es inevitable que aparezcan factores no considerados. También resulta imposible porque no disponemos de una medida común que permita reducir los resultados buenos y malos a un común denominador, de modo que podamos realizar el cálculo que se nos pide.

Lo anterior no significa negar que en la vida moral haya que prever el futuro y anticipar posibles cursos causales. Habrá que hacerlo, pero mediante un razonamiento prudencial y no a través de un cálculo técnico. A diferencia de los procedimientos técnicos, el resultado de ese razonamiento normalmente no será seguro. Por lo general, solo tendremos seguridad absoluta de que hemos actuado bien cuando hemos omitido realizar un acto intrínsecamente malo. En el resto de nuestras acciones no tendremos esa seguridad, porque estaremos entregados a la calidad de nuestra prudencia. El esfuerzo en la vida moral no va encaminado tanto a que obtengamos una seguridad absoluta, sino a desarrollar estilos de conducta tales que no puedan ser mal utilizados. Es el caso de las virtudes.

Aunque fuese posible hacer un cálculo técnico, no sería deseable, pues significaría, si se toma en serio, poner sobre los hombros del agente una carga terrible de soportar, a saber, la de constituirse en juez de la historia. Sabemos, por ejemplo, que muchos actos malos han sido seguidos de algunos efectos indirectos de carácter positivo, ¿significa esto que los podemos justificar?, ¿podría, por ejemplo, alguien decir que el horror de Auschwitz resulta compensado por la simpatía general de que goza hoy el pueblo judío en todas partes? Es indudable que lo ocurrido allí ayudó a remover la conciencia de la humanidad para que reconociera la dignidad de un pueblo. Pero Auschwitz sigue siendo Auschwitz y no resulta un milímetro menos malo porque haya logrado una consecuencia positiva en el largo plazo, por muy importante que esta pudiera ser. Cuando uno se ve enfrentado a la posibilidad de realizar un acto semejante, debe detenerse sin que tenga sentido imaginar escenarios o calcular consecuencias futuras que podría proporcionar una 
justificación para hacerlo. Siempre cabe encontrar razones para hacer algo malo. Por eso dice Eneas a Aquiles que "versátil es la lengua de los mortales; en ella hay razones de toda índole, y el pasto de palabras es copioso aquí y allá" 5 . Pero esas razones no son tales que sean capaces de eliminar las razones para no hacer el mal.

Un famoso caso judicial ocurrido en Alemania ayudará a ilustrar la diferencia que existe entre admitir o no ciertos límites infranqueables, más allá de los cuales cesa el cálculo de las consecuencias. Se trataba de un triángulo amoroso al interior de una secta. La mujer y su amante deciden eliminar al marido de ella, para lo cual recurren a otro adepto de esa agrupación. Le explican que, por una revelación especial, han sabido que el mundo va a sufrir una invasión de los gatos, que terminarán por dominar a todos los hombres. Sin embargo, para que esta operación tenga éxito, los felinos deben contar con un hombre, el "Rey de los gatos", que sirva de nexo y permita llevar a cabo el plan. Ese hombre casualmente es el marido de la mujer. Se le pide, entonces, que se sacrifique por la humanidad y dé muerte a ese hombre, para evitar así un daño de grandísimas proporciones. ¿No es legítimo sacrificar la propia conciencia con tal de evitar la esclavitud presente y futura de todos los seres humanos? El aludido acepta la proposición y da muerte al marido de la interesada. En el juicio se acreditó que el homicida no estaba demente y que había obrado en uso de su razón. La defensa alegó que por su parte había existido una buena intención, pues no había obrado motivado por intereses personales, sino por una preocupación por el bienestar de la humanidad. Los tribunales no acogieron esa defensa y condenaron al homicida, aduciendo que ningún cálculo de consecuencias podía justificar el que se tratara a una persona, en este caso la víctima, como un simple medio para el logro de otros intereses ${ }^{6}$. Cuando actuamos, nunca sabemos todo lo que podríamos o querríamos saber. La única excepción está dada por esos actos que sabemos que son siempre malos, pues ese conocimiento es completamente suficiente para excluirlos de nuestro curso de acción. Dicho con otras palabras, en moral el conocimiento más seguro tiene un carácter negativo. Por eso dice Aristóteles que "hay quizá cosas a las que uno no puede ser forzado, sino que debe preferir la muerte tras terribles sufrimientos: así, las causas que obligaron al Alcmeón de Eurípides a matar a su madre resultan ridículas"7.

La aceptación de normas morales de carácter absoluto no significa petrificar la vida de los individuos ni poner cortapisas al despliegue

Ilíada XX 248-9.

6 Sentencia del Tribunal Supremo Federal alemán de 15 de septiembre de 1988 (BGHSt 35, 347),

EN 1110a27 ss. 
de su libertad. De una parte, ellas son muy pocas, y solo marcan el límite que impide caer en actos de inhumanidad. De otra, como se ha dicho muchas veces ${ }^{8}$, el problema fundamental de la vida de las personas correctas no es la de elegir entre el bien y el mal, sino entre lo mejor y lo peor, y este diario problema solo se puede ir resolviendo en la medida en que el hombre aspire no a simplemente evitar transgredir unos mínimos, sino a desenvolver todas sus capacidades de una manera que armonice con las exigencias de su situación. Por último, el contar con ciertos límites nos pone enfrente la existencia de seres que son más débiles que nosotros y las exigencias que derivan de la dignidad humana, que impide que la reduzcamos a la condición de un simple instrumento que se sacrifica para lograr finalidades supuestamente más altas. La existencia de normas morales que no admiten excepción, es una garantía para aquellas personas que, por su desmedrada situación física, psíquica o económica, pueden ser objeto de subordinación a los intereses de hombres más poderosos. Ante estas normas no hay personas privilegiadas. Nadie puede sustraerse de sus exigencias.

La doctrina clásica de los absolutos morales lleva, en definitiva, a dar ante estos casos, la misma respuesta que le dio Alyosha a su hermano Iván Karamazov, porque la tradición filosófica no ha hecho más que apoyar en razones más fundamentadas una intuición que mantienen muchos hombres de buena voluntad, de modo a veces inconsciente o poco reflexivo:

"Respóndeme con franqueza. Si los destinos de la humanidad estuviesen en tus manos, y para hacer definitivamente feliz al hombre, para procurarle al fin la paz y la tranquilidad, fuese necesario torturar a un ser, a uno solo, a esa niña que se golpeaba el pecho con el puñito, a fin de fundar sobre sus lágrimas la felicidad futura, ¿te prestarías a ello? Responde sinceramente".

- "No, no me prestaría"9.

Los llamados absolutos morales nos hacen recordar que hay fronteras entre lo humano y lo inhumano, que nuestra acción no se da en el vacío sino en la coexistencia con nuestros semejantes, y que no somos nosotros los que determinamos el sentido último de la realidad. Con todo, el respeto de esas normas no basta para ser una buena persona.

8 Cfr. F. Inciarte, "Ética y política en la filosofía práctica", en íd. El reto del positivismo lógico Madrid: Rialp, 1974; 213.

9 Dostolevski, F. Los hermanos Karamazov, II, V. 
Ellas marcan tan solo un mínimo, es decir, protegen diversos bienes cuya lesión significa que el sujeto está reduciendo a la humanidad, ya sea la propia o la ajena, a la condición de cosa, que está destruyendo algún aspecto de la plenitud humana. Pero la vida moral no acaba allí, sino que se dirige a vivir bien, a alcanzar la excelencia humana. Si alguien piensa que es bueno simplemente porque no le hace mal a nadie, es señal de que no ha entendido nada.

\section{Bibliografía CONSULTADA}

- Finnis, J.: Absolutos morales, Barcelona, Ediciones Internacionales Universitarias, 1992

- MAY, W. (ed.): Principios de vida moral, Barcelona, Ediciones Internacionales Universitarias, 1990

- Spaemann, R.: Felicidad y benevolencia, Madrid, Rialp, 1991.

- Curran, Ch., McCormick, R.A. (eds.): Readings in Moral Theology, 1. Moral Norms and Catholic Tradition New York, Paulist Press, 1979.

- Ramsey, P., McCormick, R.A. (eds.): Doing Evil to Achieve Good Chicago, Loyola University Press, 1978.

- Molina, E.: La Moral entre la Convicción y la Utilidad Pamplona, Eunsa, 1996.

- Pinkaers, S.: Ce qu'on en peut jamais faire. La question des actes intrinsèquement mauvais. Histoire et discussion, Fribourg (Suisse), Éditions Universitaires de Fribourg, 1986.

- Baron, M. et al:: Three Methods of Ethics - A Debate: For and Against: Consequences, Maxims, and Virtues, Oxford, Blackwell, 1997.

- Petrit, Ph. (ed.): Consequentialism (International Research Library of Philosophy, Vol 6). Dartmouth, Aldershot, 1993.

- Roberts, M.A.: Child Versus Childmaker: Future Persons and Present Duties in Ethics and the Law (Studies in Social, Political, and Legal Philosophy), Lanham, Rowman \& Littlefield, 1998.

- Cummiskey, D.: Kantian Consequentialism New York: OUP, 1996, y CARlson, E. Consequentialism Reconsidered Dordrecht: Kluwer Academic Publishers, 1995.

- Herrera, H.: Verdad y práctica. Cinco ensayos sobre la fundamentación de la praxis, Valparaíso, Edeval, 2000.

- AввÀ, G.: Felicidad, vida buena y virtud. Ensayo de filosofía moral, Barcelona, Ediciones Internacionales Universitarias, 1992.

- Nussbaum, M.: Love's Knowledge Oxford, Oxford University Press, 1990.

- Inciarte, F.: "Ética y política en la filosofía práctica", en íd. El reto del positivismo lógico, Madrid, Rialp, 1974. 